\title{
Ibuprofen/ $\beta$-CD complexation by controlled annealing of their mechanical mixture
}

\author{
St. Pereva ${ }^{1}$, Ts. Sarafska ${ }^{1}$, V. Petrov ${ }^{2}$, M. Spassova ${ }^{1}$, S. Bogdanova ${ }^{1}$, T. Spassov ${ }^{1 *}$ \\ ${ }^{1}$ University of Sofia "St. Kl. Ohridski”, Faculty of Chemistry and Pharmacy, Department of Applied Inorganic \\ Chemistry, 1, J. Bourchier str., 1164 Sofia, Bulgaria \\ ${ }^{2}$ University of Sofia "St. Kl. Ohridski", Faculty of Chemistry and Pharmacy, Department of Physicochemistry, 1, J. \\ Bourchier str., 1164 Sofia, Bulgaria
}

Received July 12, 2018, Accepted March 7, 2019

Ibuprofen/ $\beta$-cyclodextrin complex was formed applying a modified melting method, consisting in melting only the drug in the mechanical mixture of ibuprofen and $\beta$-cyclodextrin. The ibuprofen inclusion into $\beta$-CD was monitored by differential scanning calorimetry after initial release of the water molecules from the CD cavity and was proved by X-ray diffraction and FTIR analyses.

Keywords: $\beta$-cyclodextrin, ibuprofen, inclusion complex, melting method

\section{INTRODUCTION}

Cyclodextrins are natural cyclic oligosachharides consisting of $(\alpha-1,4)$-linked $\alpha$-Dglucopyranose units with a cavity able to host foreign molecules. In pharmacy, cyclodextrins are mainly used as complexing agents to increase the aqueous solubility of poorly water-soluble drugs, and to increase their bioavailability and stability [1$6]$. The main and most studied cyclodextrins are $\alpha$-, $\beta$ - and $\gamma$-cyclodextrin, which differ from one another by the number of repeating glucose units. From the three natural cyclodextrins, $\beta-C D$ is the most used in the pharmaceutical industry due to the cavity size, availability and low cost [7].

Ibuprofen ((RS)-2-(4-(2-methylpropyl)phenyl) propanoic acid) is a nonsteroidal anti-inflammatory drug (NSAID), commonly administered for treatment of fever, pain and inflammation. The drug is $\mathrm{pH}$-dependent and practically insoluble in water. Throughout the years, a variety of ibuprofen (IBU) complexes with $\beta$-cyclodextrin and its derivatives were synthesized and studied, aiming to increase ibuprofen water solubility [8-10]. Inclusion compounds with ibuprofen and $\beta$-cyclodextrin have been studied using different synthetic methods kneading [11], solid dispersion [11-15], freeze/spray drying [11-16], super-critical $\mathrm{CO}_{2}[17$, 18], microwave treatment [18, 19], ball milling [2023], sealed heating $[16,18,20]$, etc. Solid dispersion (SD) method is one of the most applied methods for preparation of inclusion compounds. The advantages that the solid dispersion method provides are high purity of the inclusion compound, particle size reduction, high crystallinity. Although, the method is long, it needs large quantities of solvent and energy and there is a risk of

\footnotetext{
* To whom all correspondence should be sent: E-mail: tspassov@chem.uni-sofia.bg

cyclodextrin-solvent reaction.

Melting and solvent evaporation methods are other techniques of preparing inclusion compounds $[16,18]$. Sekiguchi and Obi proposed in 1961 the melting technique, aiming to achieve reduction of particle size and to increase the dissolution rate and absorption $[24,25]$. In this technique, the physical mixture of a drug and a water-soluble carrier is heated directly to melting. The melting point of a binary system depends on the selection of the carrier and the weight fraction of the drug in the system. The melted mixture is then cooled and rapidly solidified in an ice bath under rigorous stirring. The final solid mass is crushed, pulverized, sieved, and then compressed into tablets. For the complex formation by the hot melt method the miscibility of the drug and carrier in the molten form and their thermostability are important. The molecular mobility of the carrier also plays an important role, because it can change the drug's incorporation. To reduce the process temperature, a commonly used adaptation is applied to the melting phase, which consists of suspending the active drug in a previously melted carrier, instead of using both drug and carrier in the melted state. The main advantage of this technique is its simplicity and economy. For enhancing this method, a few modifications have been introduced over the years like hot-stage extrusion [26-28], Meltrex ${ }^{\mathrm{TM}}$ [29] and melt agglomeration [30, 31]. In the hot-stage extrusion the drug and carrier, previously mixed, extruded at high rotational speed, at melting temperature for a short period. The product is then collected after cooling at room temperature and milled. Meltrex ${ }^{\mathrm{TM}}$ is another manufacturing process. The new element in this technology is the use of a special twin extruder and the presence of two independent hoppers, which control the 
St. Pereva et al.: Ibuprofen/ $\beta$-CD complexation by controlled annealing of their mechanical mixture temperature range and expand it. The process permits a reduced residence of the drug in the extruder, thus allowing a continuous mass flow and avoiding thermal stress to the drug. Another positive side of this technique is the possibility of protecting the drugs to oxidation and hydrolysis by complete elimination of oxygen and moisture from the mixture [29].

Melt agglomeration allows the preparation of complexes in conventional high-shear mixers. This method also allows production in a rotary processor. There are three techniques for production by melt agglomeration - by adding the molten carrier containing the drug to the heated excipients; by adding the molten carrier to a heated mixture of drug and excipients; or by heating a mixture of the drug, carrier and excipients to a temperature within or above the melting range of the carrier [30, 31].

A variation of the melting method consists in heating the mechanical mixture to the melting of the drug only, as the CD is solid. Thus, the complex is formed due to facilitated diffusion of the molten component of the mixture. To the best of our knowledge, this method has only been applied for naproxen (NP)/ $\beta-C D$ complex formation [32]. Grandelli et al. used a wide range of NP: $\beta-C D$ molar ratios $(0.5: 1$ to $5: 1)$ and their results showed that the complexation via the physical mixture is influenced by transport limitations and also $\beta$ $\mathrm{CD}$ :NP ratios. According to them, ratios greater than 2:1 lead to higher efficiency of complexation.

The goal of this work was to examine the formation of inclusion complex between ibuprofen and $\beta$-cyclodextrin by annealing their mechanical mixture at a temperature above the melting temperature of ibuprofen and far enough from the decomposition temperature of $\beta-\mathrm{CD}$ and ibuprofen.

\section{MATERIALS AND METHODS}

$\beta$-cyclodextrin was purchased from Wacker Chemie AG, Germany and ibuprofen was purchased from Teva Pharmaceuticals. Both reagents are of analytical grade with purity of 99.9 $\%$.

\section{Preparation of ibuprofen- $\beta$-cyclodextrin mechanical mixture}

Ibuprofen and $\beta$-cyclodextrin were mixed in a molar ratio of $1: 1$ in dry conditions at room temperature. This mixture was further used for all thermal annealing experiments (DSC at scanning and isothermal conditions) aiming to form inclusion complexes.
Characterization of the mechanical mixture and the ibuprofen/ $\beta$-cyclodextrin complex

The thermal behavior of ibuprofen $/ \beta$ cyclodextrin mechanical mixture, as well as of the pure substances was characterized with PerkinElmer DSC-7 differential scanning calorimeter under pure Ar atmosphere. The heating/cooling experiments were carried out with a rate of 5 and $10{ }^{\circ} \mathrm{C} / \mathrm{min}$, respectively. The structure and microstructure of cyclodextrin, ibuprofen and their complex were studied by $\mathrm{X}$-ray diffraction with $\mathrm{Cu}$ $\mathrm{K} \alpha$ radiation (Bruker D8 Advance diffractometer).

The Attenuated Total Reflectance Fourier Transform InfraRed (ATR-FTIR) spectra of $\beta$-CD, ibuprofen and the melting complex were recorded on Bruker Tensor 27 FT spectrometer by direct deposition on a diamond ATR crystal, with 64 scans at a resolution of $2 \mathrm{~cm}^{-1}$ in the middle IR region $\left(600-4000 \mathrm{~cm}^{-1}\right)$.

\section{RESULTS AND DISCUSSION}

The thermal behavior of pure ibuprofen and $\beta$ $\mathrm{CD}$ in the temperature range of $40{ }^{\circ} \mathrm{C}$ to $140{ }^{\circ} \mathrm{C}$ is presented in Figure 1a. The sharp endothermic peak of the pure drug at $78{ }^{\circ} \mathrm{C}$ indicates its melting, while $\beta$-CD shows a broad endothermic effect in the range of $80-140{ }^{\circ} \mathrm{C}$, associated with water release from the inner cavity of the cyclodextrin molecule. The melting enthalpy of ibuprofen $\left(\Delta \mathrm{H}^{\mathrm{m}}\right)$ was determined to be $127 \mathrm{~J} / \mathrm{g}$, corresponding to that of racemic ibuprofen [33].

It was already shown that the DSC melting peak of the drug (in this case ibuprofen) can be used to determine if a drug/CD host-guest complex is formed, as well as to obtain the degree of complexation at various conditions of the drug inclusion $[32,34]$. The distinct melting peaks in the DSC scans do not appear if the entire drug is included in the cyclodextrin cavity, while reduction of the drug melting enthalpy, measured by DSC, is an indication for partial complex formation [34]. As already argued, in order to form the desired inclusion complex we started from a mechanical mixture of ibuprofen and $\beta$-CD in molar ratio of $1: 1$ [34]. The thermal analysis for the mechanical mixture is presented in Figure $1 \mathrm{~b}$ and shows two endothermic peaks. The first one indicates the melting of drug, and the second one is associated with water release from $\beta$-CD. The shift with $6{ }^{\circ} \mathrm{C}$ to lower temperatures (from $78{ }^{\circ} \mathrm{C}$ to $72{ }^{\circ} \mathrm{C}$ ) of the ibuprofen melting peak can only be explained with the presence of solid particles of $\beta-C D$ in the ibuprofen $/ \beta-C D$ mixture. 

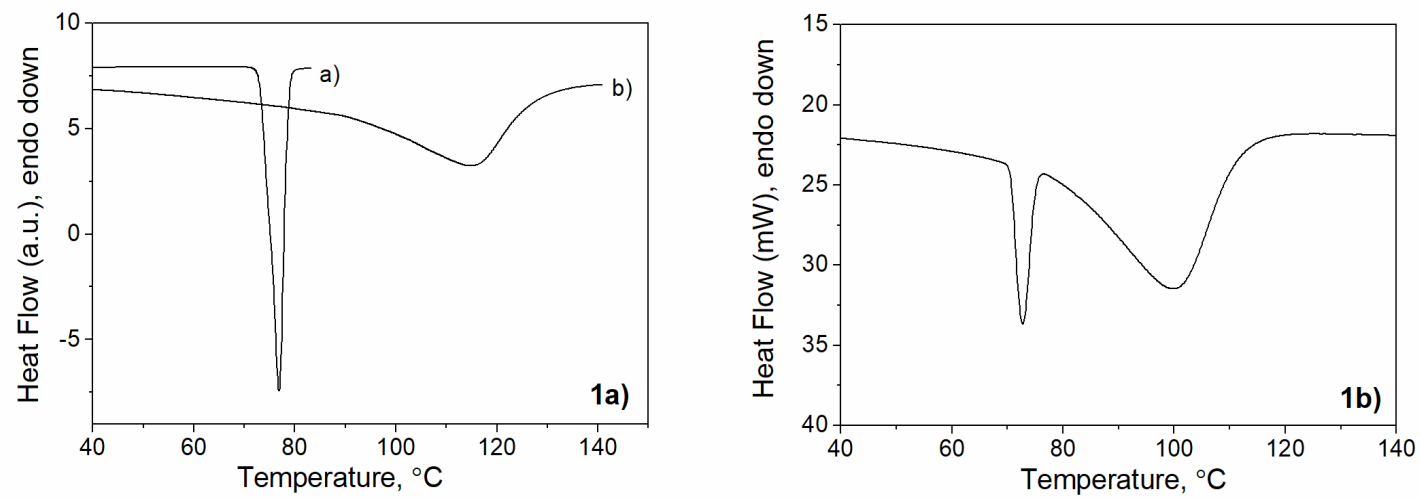

Figure 1. (a) DSC curves of pure (a) ibuprofen and (b) $\beta$-cyclodextrin; (b) DSC curve of ibuprofen/ $\beta$-CD mechanical mixture.

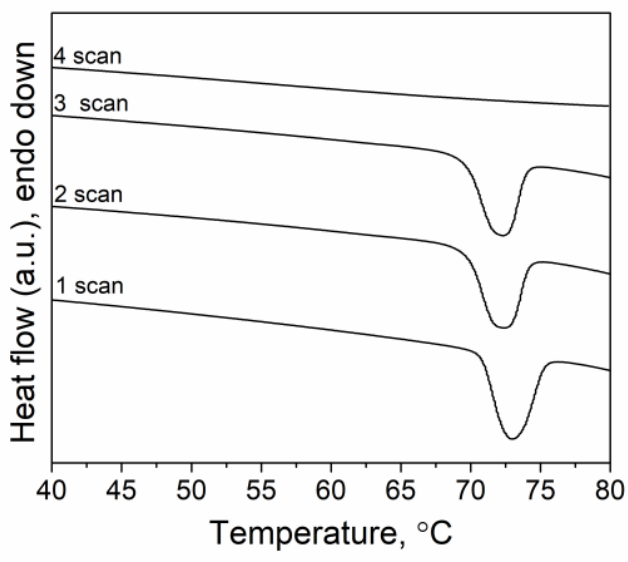

Figure 2. DSC scans of ibuprofen/ $\beta-C D$ mechanical mixture (1:1 molar ratio).

Figure 2 reveals successive DSC scans of ibuprofen/ $\beta-C D$ mechanical mixture in the temperature range $40-80{ }^{\circ} \mathrm{C}$. In the first three heating/cooling runs (with heating/cooling rate of $10 \mathrm{~K} / \mathrm{min}$ ) the ibuprofen melting peak is clearly observed. The melting enthalpies of ibuprofen in the first three runs decrease in the following order: $116 \mathrm{~J} / \mathrm{g}, 106 \mathrm{~J} / \mathrm{g}$ and $105 \mathrm{~J} / \mathrm{g}$, respectively, for the first, second and third heating run, giving in this way an indication for a very small degree of complex formation reached at these annealing conditions. Only when the mixture was preliminary annealed at $80{ }^{\circ} \mathrm{C}$ for $30 \mathrm{~min}$ and then heated up with a constant rate to $80^{\circ} \mathrm{C}$ the endothermic melting peak was not detected $\left(4^{\text {th }}\right.$ scan). This result is an obvious indication that the sample already contains no free ibuprofen due to its interaction in a molten state with the solid cyclodextrin.

In contrast to the inclusion of naproxen into $\beta$ $\mathrm{CD}$, realized applying the above described thermal regime of heating [32], annealing the ibuprofen $/ \beta$ $\mathrm{CD}$ mechanical mixture at a scanning regime to a temperature above the melting temperature of ibuprofen does not result in complexation, Figure 2. Annealing naproxen/ $\beta-C D$ mixture in DSC to a temperature above the endothermic melting peak (at $\mathrm{T}>\mathrm{T}^{\mathrm{m}}$ of naproxen) results in naproxen/ $\beta-\mathrm{CD}$ complex formation (inclusion of the drug into the $\beta$-CD cavities) [32]. The reason why ibuprofen $/ \beta$ $\mathrm{CD}$ mechanical mixture does not form a complex at these annealing conditions should be sought in the lower rate of ibuprofen inclusion into $\beta-C D$ compared to naproxen $/ \beta-C D$. Apparently, for the ibuprofen/ $\beta-C D$ complex formation longer annealing time or higher temperature of annealing are required to overcome the diffusion difficulties of the drug insertion.

With the aim to register by DSC the interaction between ibuprofen and $\beta-\mathrm{CD}$, the following experiment was carried out: the mechanical mixture at a molar ratio of $1: 1$ was initially annealed in DSC under isothermal conditions at $65{ }^{\circ} \mathrm{C}$ for 1 hour. The temperature and the annealing time were selected/optimized so as to allow the complete release of the water molecules from the cyclodextrin without melting the ibuprofen. The idea of this heat treatment is releasing of the pores of $\beta$-CD from the water to ease the incorporation of ibuprofen molecules into the already hollow pores. Then, immediately, without removing the sample from the DSC, subsequent annealing was carried out from room temperature to $130{ }^{\circ} \mathrm{C}$ at a scanning rate of $5 \mathrm{~K} / \mathrm{min}$, Figure 3 . The final temperature $\left(130{ }^{\circ} \mathrm{C}\right)$ was adjusted so, as to avoid ibuprofen decomposition. At first look, the observed DSC curve contains only an endothermic ibuprofen's melting peak with a melting enthalpy corresponding to pure ibuprofen, $116 \mathrm{~kJ} / \mathrm{mole}$. When changing the scale of the DSC signal in the temperature range $100-130^{\circ} \mathrm{C}$, a broad exothermic effect (peak) with enthalpy change of around 21 $\mathrm{kJ} /$ mole was observed (Figure 3, inset), which can 
St. Pereva et al.: Ibuprofen/ $\beta$-CD complexation by controlled annealing of their mechanical mixture only be associated with the reaction between the two components of the mechanical mixture. Due to the low speed of ibuprofen inclusion into the $\beta-C D$ and relatively weak interaction between them, the effect is bare and with low enthalpy change. It is important to note that without the prior release of the $\beta$-CD cavities from the water molecules, the ibuprofen inclusion reaction could not be monitored by DSC. The enthalpy of ibuprofen inclusion appears to be comparable to that determined by Grandelli [32] for naproxen/ $\beta$-CD complexation.

Figure 3. DSC curve of the mechanical mixture of ibuprofen/ $\beta$-CD (1:1) after initial isothermal annealing at

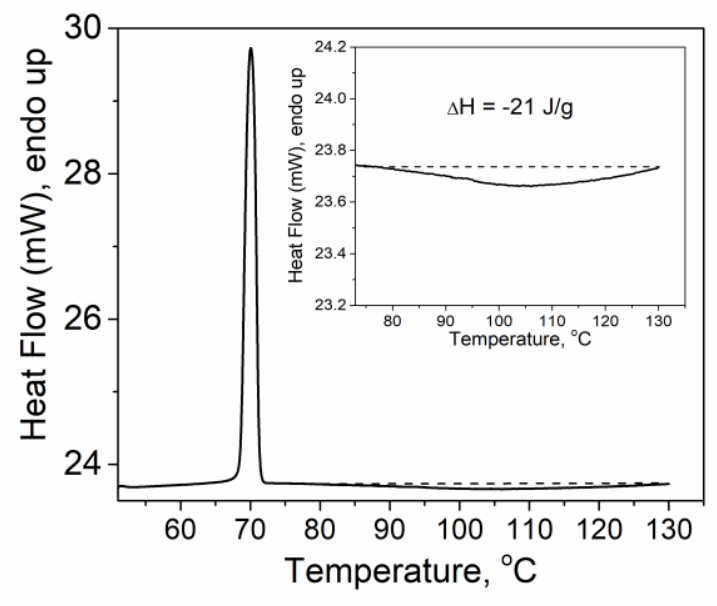

$65^{\circ} \mathrm{C}$ for $1 \mathrm{~h}$

To verify if ibuprofen has reacted completely during the above described annealing of the mechanical mixture FT-IR analysis was performed. The FT-IR spectra of the host, the complex obtained by the melting method and the guest are presented in Figure 4. In order to estimate the differences between the complex and the possible mechanical mixture, a spectral subtraction based on Excel Solver optimization was performed according to eq. (1):

$$
A_{\text {Difference }}=\left[A_{\text {complex }}-\alpha A_{\beta-C D}-\beta A_{I B U}\right]^{2} \rightarrow \min
$$

where $A_{\mathrm{x}}$ is the absorbance of the respective substance and $\alpha, \quad \beta$ are optimized scaling coefficients. The inset of Figure 4 indicates peaks that suffered shape modifications or shifts. As expected, the maximum displacement can be observed at the hydroxyl group band of the host located around $3265 \mathrm{~cm}^{-1}$ and the carbonyl group band of the guest, located around $1705 \mathrm{~cm}^{-1}$, groups where possible hydrogen bonds are typically formed. Observed shifts and changes of the spectral shape are good evidences for complex formation. Lack of changes of the methyl groups bands suggests that this groups most probably are located outside of the host cavity.

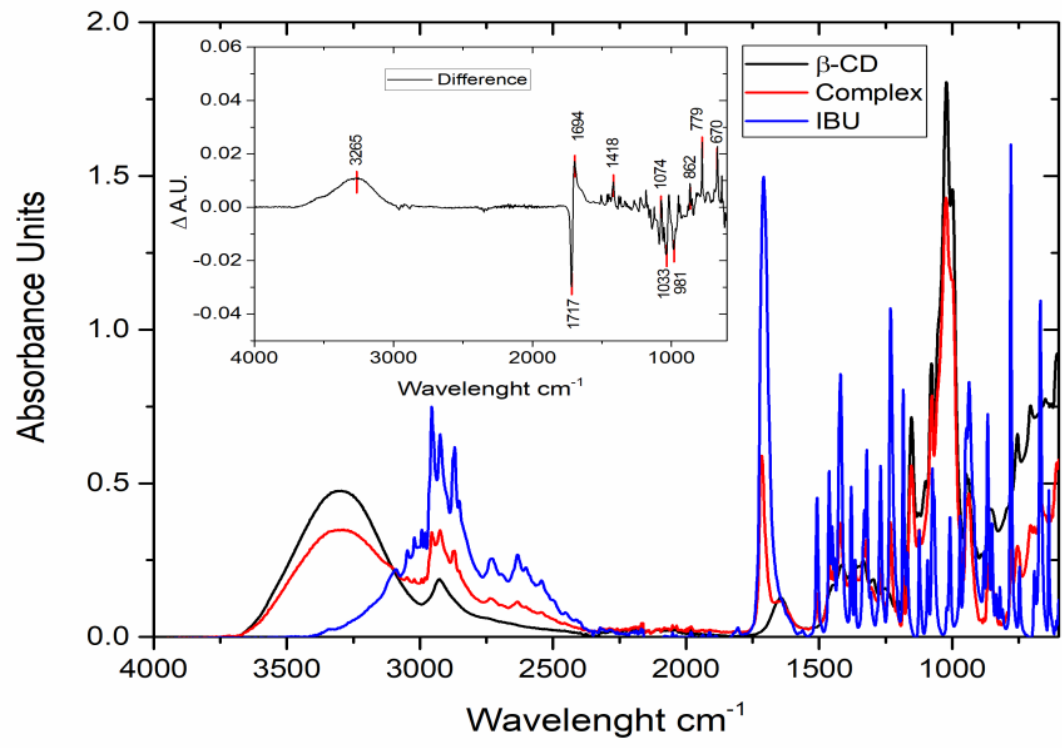

Figure 4. FT-IR spectra of $\beta-C D$, ibuprofen and ibuprofen $/ \beta-C D$ complex. Inset: The difference between simulated mixture of $\beta-C D$ and ibuprofen and the complex spectra. 
St. Pereva et al.: Ibuprofen/ $\beta$-CD complexation by controlled annealing of their mechanical mixture Additional proof for the formation of the inclusion complex was obtained by X-ray diffraction analysis. Figure 5 shows the XRD patterns of ibuprofen, $\beta-C D$, and the inclusion complex formed by the "melting" method. Qualitatively different is the X-ray diffraction pattern of the inclusion complex showing the presence of new crystalline peaks and the disappearance of these of ibuprofen. The new diffraction peaks are broader and with

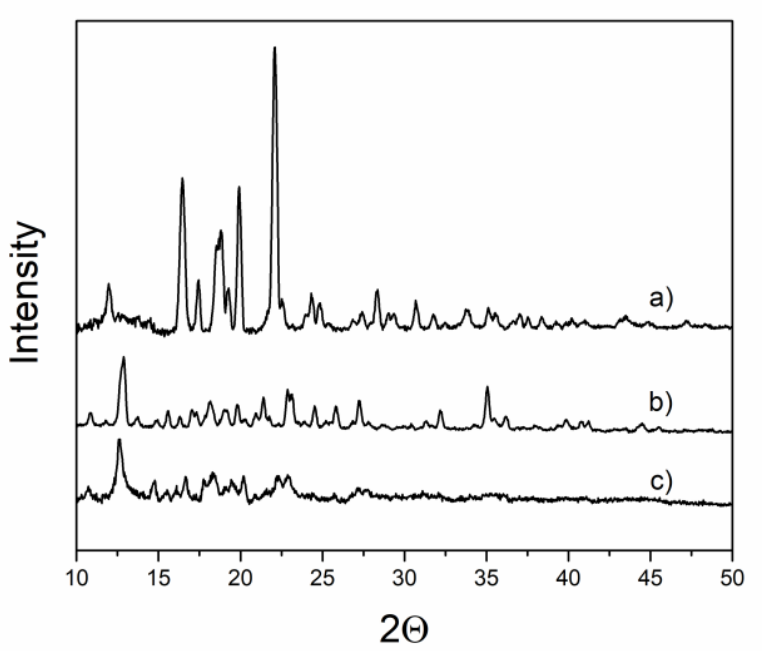

reduced intensity, revealing a nanocrystalline nature of the complex formed.

Figure 5. XRD of (a) ibuprofen, (b) $\beta-C D$ and (c) inclusion complex obtained by the "melting" method.

\section{CONCLUSIONS}

To form ibuprofen/ $\beta$-cyclodextrin inclusion complex, a mechanical mixture of the two components was isothermally annealed at a temperature below the melting point of ibuprofen, but high enough to release the water molecules from $\beta-C D$. At these heat treatment conditions $(1 \mathrm{~h}$ at $65{ }^{\circ} \mathrm{C}$ ) no interaction between ibuprofen and $\beta$ $\mathrm{CD}$ molecules takes place. However, in subsequent annealing in DSC at a constant rate, the reaction proceeds and is observed as a broad exothermic peak in the range $80-130^{\circ} \mathrm{C}$. The enthalpy of the drug inclusion $(-21 \mathrm{~J} / \mathrm{g})$ was determined to be comparable to that of the naproxen inclusion in $\beta$ $\mathrm{CD}$ [32]. In addition, it was found that applying the melting method complete complex formation was achieved even at 1:1 ibuprofen/ $\beta$-CD molar ratio. The modified melting method applied in this work allows quantitative investigation of the drug inclusion kinetics, which is a subject of a current study.

1. S. Vaidya, Resonance, 9, 18 (2004).

2. E. Bilensoy, D. Duchene, A. Ahuja, S. Baboota, J. Ali, G. Mustafa, F. Acartürk, N. Celebi, Part 1, Ch. 1 \& Ch. 3, Cyclodextrins in pharmaceutics, cosmetics and biomedicine, John Wiley \& Sons, Inc., Hoboken, New Jersey, 2011, p. 3.

3. T. Loftsson, D. Duchene, Int. J. Pharm., 329, 1 (2007).

4. L. Liu, Q. X. J. Guo, Inclusion Phenom. Macrocyclic Chem., 42, 1 (2002).

5. M. E. Brewster, T. Loftsson, Adv. Drug Delivery Rev., 59, 645 (2007).

6. K. Uekama, Design and evaluation of cyclodextrinbased drug formulation, Chem. Pharm. Bull., 52, 900 (2004).

7. F. Trotta, R. Cavalli, K. Martina, M. Biasizzo, J. Vitillo, S. Bordiga, P. Vavia, K. Ansari, J. Incl. Phenom. Macrocycl. Chem., 71, 189 (2011).

8. P. J. Salústio, G. Feio, Eur. J. Pharm. Biopharm., 71, 377 (2009).

9. P. Mura, A. Bettinetti, Int. J. Pharm., 166, 189 (1998).

10. G. M. Khan, Jia-Bi Zhu, J. Chinese Pharm. Sci., 7, 72 (1998).

11. T. Vasconcelos, B. Sarmento, P. Costa, Drug Discovery Today, 12, 1068 (2007).

12. W.L. Chiou, S. Riegelman, J. Pharm. Sci., 60, 9 (1971).

13. T. Vilhelmsen, H. Eliasen, T. Schaefer, Int. J. Pharm., 303, 132 (2005).

14. V.B. Pokharkar, L.P. Mandpe, M.N. Padamwar, A.A. Ambike, K.R. Paradka, Powder Technol., 167, 20 (2006).

15. D-H. Won, M-S. Kim, J-S. Park, S-J. Hwang, Int. J. Pharm., 301, 199 (2005).

16. A.H. Al-Marzouqi, H.M. Elwy, I. Shehadi, A. Adem, J. Pharm. Biomed. Anal., 49, 227 (2009).

17. P. York, Pharm. Sci. Technol. Today, 2, 430 (1999).

18. M. Cirri, F. Maestrelli, N. Mennini, P. Mura, J. Pharm. Biomed. Anal., 50, 690 (2009).

19. X.H. Wen, F. Tan, Z.J. Jing, Z.Y. Liu, J. Pharm. Biomed. Anal., 34, 517 (2004).

20. A. Al-Marzouqi, B. Jobe, G. Corti, M. Cirri, P. Mura, J. Incl. Phenom. Macrocycl. Chem., 57, 2233 (2007).

21. J.S. Patil, D.V. Kadam, S.C. Marapur, M.V. Kamalapur, Int. J. Pharm. Sci. Review Res., 2, 29 (2010).

22. Q. L. Sanming, X. Che, X. Fan, C. Lib, Asian J. Pharm. Sci., 5, 188 (2010).

23. I. Colombo, G. Grassi, M. Grassi, J. Pharm. Sci., 98, 3961 (2009).

24. K. Sekiguchi, N. Obi, Chem. Pharm. Bull., 9, 866 (1961).

25. K. Sekiguchi, N. Obi, Chem. Pharm. Bull. (Tokyo), 12, 134 (1964).

26. C.W. Pouton, Eur. J. Pharm. Sci., 29, 278 (2006).

27. G. Verreck, A. Decorte, K. Heymans, J. Adriaensen, D. Cleeren, A. Jacobs, D. Liu, D. Tomasko, A. 
St. Pereva et al.: Ibuprofen/ $\beta$-CD complexation by controlled annealing of their mechanical mixture Arien, J. Peeters, P. Rombaut, G. Van den Mooter, ME. Brewster, Eur. J. Pharm. Sci., 26, 349 (2005).

31. A. Seo, P. Holm, H. G. Kristensen, T. Schaefer, Int. J. Pharm., 259, 161 (2003).

28. G. Van den Mooter, I. Weuts, T. De Ridder, N. Blaton, Int. J. Pharm., 316, 1 (2006).

29. J. Breitenbach, J. Lewis, Two concepts, one technology: controlled release and solid dispersion with meltrex, in: Modified-Release Drug Delivery Technology (M.J. Rathbone et al., eds.), Marcel Dekker, 2003, p. 125.

30. M.K. Gupta, Y-C. Tseng, D. Goldman, R.H. Bogner, Pharm. Res., 19, 1663 (2002).

32. H. E. Grandelli, B. Stickle, A. Whittington, E. Kiran, J. Inclusion Phenomena, 77, 269 (2013).

33. S. Lerdkanchanaporn, D. Dollimore, A Thermal Analysis Study of Ibuprofen, J. Thermal Analysis, 49, 879 (1997).

34. St. Pereva, Tzv. Sarafska, Sv. Bogdanova, T. Spassov, J. Drug Delivery Sci. Technol., 35, 34 (2016). 